\title{
Performance Characteristics of a Stirred-Tank Reactor with a Mechanical Foam-Breaker Utilizing Shear Force
}

\author{
Satoshi TAKESONO ${ }^{1}$, Masayuki ONODERA ${ }^{1}$, \\ Masanori YosHIDA ${ }^{2}$, Kazuaki YAMAGIWA ${ }^{2}$ \\ and Akira OHKAWA ${ }^{2}$ \\ ${ }^{1}$ Department of Applied Chemistry and Biotechnology, \\ Niigata Institute of Technology, 1719, Fujihashi, \\ Kashiwazaki-shi, Niigata 945-1103, Japan \\ ${ }^{2}$ Department of Chemistry and Chemical Engineering, \\ Niigata University, 8050, Ikarashi 2, Niigata-shi, \\ Niigata 950-2181, Japan
}

Keywords: Stirred-Tank Reactor, Foam-Breaker, Shear Force, Foam-Breaking Power, Oxygen Transfer Performance

\begin{abstract}
A new mechanical foam-breaker was developed. It uses the shear force between a fixed orifice plate and a rotating disk (MFUS). Foam-breaking performance of the MFUS fitted to a stirred-tank reactor (STR) was evaluated from changes in foam density and shearing power. The maximum value of the ratio of foam density (after foam breaking) to liquid density was 0.90 . Change in foam densities before and after foam breaking in the MFUS was considerably larger than that in existing mechanical foam-breakers with rotating parts at the same level of power for foam breaking. The volumetric liquid-phase oxygen transfer coefficient was measured in the bubble-dispersing and foam-ascending sections of the STR with the MFUS. Comparison of the volumetric liquid-phase oxygen transfer coefficient between the STR with the MFUS and the STR or the foam column in terms of the specific power input demonstrated higher oxygen transfer performance and saving power requirements for the STR with the MFUS.
\end{abstract}

\section{Introduction}

Undesirable foaming frequently occurs in gasliquid contacting operations using a reactor with gas sparging transport. It decreases the working liquid volume. Additionally, reactants and products accumulate in the foam and may be lost from the reactor along with the escape of foam. Consequently, the aerationagitation rate may be limited unless foaming is controlled by some means (Hall et al., 1973; Viesturs et al., 1982; Ghildyal et al., 1988; Boon et al., 2002; Hoeks et al., 2003). Both chemical and mechanical methods are available for foam control. Mechanical foam-control is preferable to chemical foam-control because it avoids problems such as the lowering of the mass transfer rate, reaction inhibition, and toxicity; moreover, adverse effects on separation and purification of products occur when foaming is controlled by adding antifoam agents (Yagi and Yoshida, 1974; Andrew, 1982; Koide et al., 1985; Hoeks et al., 1997). Numerous mechanical foam-breakers have been proposed. Viesturs et al. (1982) and Ghildyal et al. (1988) have classified mechanical foam-breakers, including

Received on May 10, 2004. Correspondence concerning this article should be addressed to S. Takesono (E-mail address: takesono@acb.niit.ac.jp). many patented devices. However, most of those foambreakers are ineffective against large-scale foam masses or foam produced by high aeration and agitation, unless used in combination with antifoam agents. In other words, none of the proposed mechanical foambreakers are entirely satisfactory or universally applicable. Therefore, demand exists for development of a new type of mechanical foam-breaker that is effective for foam-control under high aeration-agitation rate conditions.

Mechanical foam-breakers cannot completely separate foams into gas and liquid phases (Gutwald and Mersmann, 1997). Primary foams ascending from the aerated liquid surface are collapsed by mechanical foam-breakers, creating very stable secondary foams with small bubbles and a high liquid holdup. In most of the proposed mechanical foam-breakers, the resultant secondary foams are returned to the area of primary foam generation and are thus accumulated in the reactor over its long lifetime. Examples include mechanical foam-breakers with rotating installations such as turbines, vaned disks, and paddles $(\mathrm{Ng}$ and Gutierrez, 1977; Deshpande and Barigou, 1999; Takesono et al., 2001, 2002). In such devices, persistent secondary foams recirculate into the foam-breaker, but cannot be broken twice by the foam-breaker. Considering that recirculation of the secondary foams into 


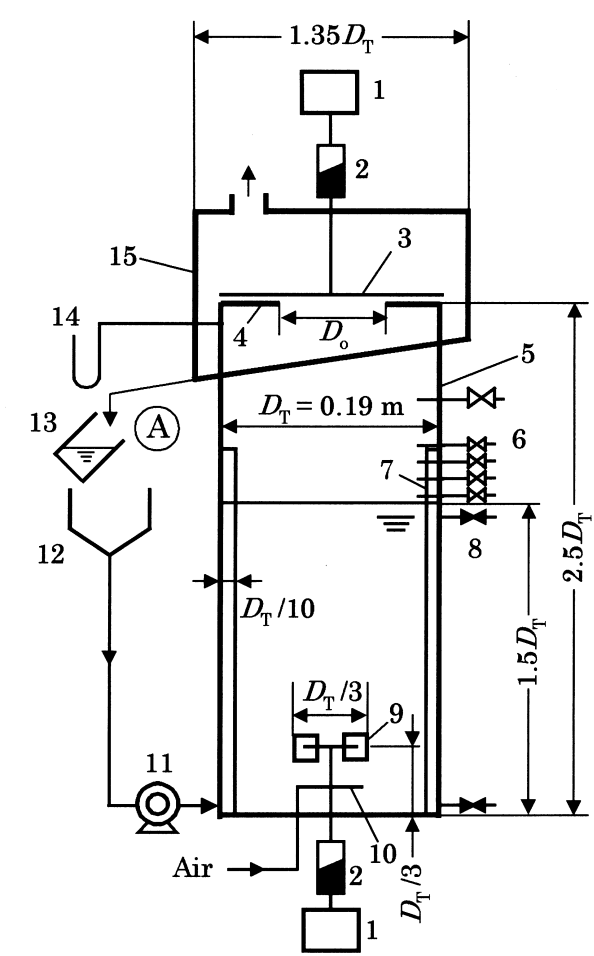

1 Motor

2 Torque meter

3 Rotating disk

4 Fixed plate having an orifice

5 Column

6 Foam sampling tap

7 Baffle plate

$\begin{aligned} 8 & \text { Manometer tap } \\ 9 & \text { Impeller } \\ 10 & \text { Ring sparger } \\ 11 & \text { Roller pump } \\ 12 & \text { Reservoir } \\ 13 & \text { Graduated cylinder } \\ 14 & \text { Manometer } \\ 15 & \text { Separation column }\end{aligned}$

Fig. 1 Schematic diagram of experimental apparatus

the foam-breaker must be avoided, we constructed a new mechanical foam-breaker (MFUS) that utilizes a shear force between a fixed orifice plate and a rotating disk. It does not return the secondary foams to the ascending area of the primary foams. This study evaluates the foam-breaking performance of the MFUS fitted to a stirred-tank reactor (STR), represented by the changes in foam density and shearing power. The gas holdup and volumetric liquid-phase oxygen transfer coefficient in the STR with the MFUS were then examined for two flow sections: bubble-dispersing and foam-ascending sections.

\section{Experimental}

\subsection{Apparatus}

Figure 1 shows a schematic diagram of the experimental apparatus. The STR, $0.19 \mathrm{~m}$ in diameter $D_{\mathrm{T}}$, was equipped with four baffles ( $D_{\mathrm{T}} / 10$ in width). A sixbladed turbine impeller $\left(D_{\mathrm{T}} / 3\right.$ in diameter) was set at a height of $D_{\mathrm{T}} / 3$ above the vessel bottom. The liquid depth was held at $1.5 D_{\mathrm{T}}$. A ring sparger with twelve holes of $0.001-\mathrm{m}$ diameter was used for air sparging. The MFUS was set at a height of $2.5 D_{\mathrm{T}}$ from the bot-

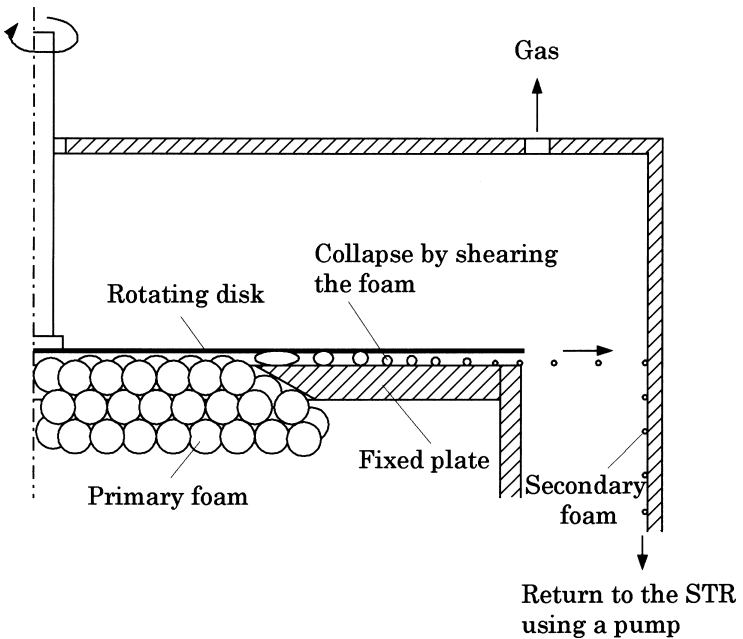

Fig. 2 Foam-breaking mechanism of the MFUS

tom. The rotating steel disk was $0.20 \mathrm{~m}$ in diameter and $0.001 \mathrm{~m}$ thick. Orifice diameters of the $0.01-\mathrm{m}$ thick fixed plate made of transparent acrylic resin were 0.06 and $0.09 \mathrm{~m}$ to change the foam-breaking area over which the shear force acts. The gap between the fixed orifice plate and the rotating disk was maintained at $0.001 \mathrm{~m}$, which was perceived to be the practical minimum gap with easy adjustment. A collapsed foam liquid-gas separation column $\left(1.35 D_{\mathrm{T}}\right.$ in diameter $)$ was mounted outside the upper part of the vessel. Primary foams passing through the orifice are forced to flow through the gap between the fixed orifice plate and the rotating disk and are collapsed by a shear force that acts on the foam, as illustrated in Figure 2. The pressure drop, which was measured by the manometer (14 in Figure 1), was less than $90 \mathrm{~Pa}$. For that reason, foam breaking by the MFUS was inferred to occur mainly through a shear force. The collapsed foam, i.e. the secondary foam, is dispersed horizontally from the edge of the gap by centrifugal force created by the rotating disk. It is collected in the separation column. Refoaming by colliding with the separation column wall was not observed within the range of this experiment. The secondary foam collected in the separation column was returned continuously to the bottom using a roller pump. The gas superficial velocity $U_{\mathrm{g}}$ ranged from $6.52 \times 10^{-3}$ to $3.10 \times 10^{-2} \mathrm{~m} \cdot \mathrm{s}^{-1}$. The impeller rotational speed $N_{\mathrm{i}}$ was varied from 10.0 to $20.0 \mathrm{~s}^{-1}$. For foam-breaking experiments, the foaming liquid (density, $998.2 \mathrm{~kg} \cdot \mathrm{m}^{-3}$; viscosity, $1.00 \times 10^{-3} \mathrm{~Pa} \cdot \mathrm{s}$; surface tension, $47.8 \times 10^{-3} \mathrm{~N} \cdot \mathrm{m}^{-1}$ ) was a diluted solution $\left(0.04 \mathrm{~g} \cdot \mathrm{L}^{-1}\right)$ of a surfactant agent Triton $\mathrm{X}-100$. For mass transfer experiments, the foaming liquid (density, $1022.6 \mathrm{~kg} \cdot \mathrm{m}^{-3}$; viscosity, $1.25 \times 10^{-3} \mathrm{~Pa} \cdot \mathrm{s}$; surface tension, $30.6 \times 10^{-3} \mathrm{~N} \cdot \mathrm{m}^{-1}$ ) was a $500 \mathrm{~mol} \cdot \mathrm{m}^{-3}$ sulfite solution to which Triton X-100 was added at a concentration of $0.1 \mathrm{~g} \cdot \mathrm{L}^{-1}$. Both liquids were maintained at $293 \pm 1 \mathrm{~K}$. 


\subsection{Foam density}

Foam density before foam breaking $\rho_{\mathrm{a}}$ was calculated as

$$
\rho_{\mathrm{a}}=\rho_{\mathrm{L}} \phi_{\mathrm{L}}+\rho_{\mathrm{g}}\left(1-\phi_{\mathrm{L}}\right)
$$

where $\rho_{\mathrm{g}}$ is the air density, $\rho_{\mathrm{L}}$ is the liquid density, and $\phi_{\mathrm{L}}$ is the liquid holdup in ascending foam. To measure $\phi_{\mathrm{L}}$, foam was withdrawn through a glass tube $(0.01 \mathrm{~m}$ in diameter) fitted on the wall $0.09 \mathrm{~m}$ below the fixed orifice plate and collected in a graduated container. $\phi_{\mathrm{L}}$ was determined from Eq. (2).

$$
\phi_{\mathrm{L}}=\frac{v_{1}}{v_{\mathrm{f}}}
$$

Therein, $v_{\mathrm{f}}$ is the volume of foam collected and $v_{1}$ is the volume of liquid remaining after the collapse of foam in the container.

The foam density after the foam breaking $\rho_{\mathrm{f}}$ was calculated from the following equation, obtained from the mass balance when the weight of the gas entrained in the collapsed foam liquid flow was neglected.

$$
\rho_{\mathrm{f}}=\frac{Q_{\mathrm{e}} \rho_{\mathrm{L}}}{Q_{\mathrm{f}}}
$$

Therein, $Q_{\mathrm{f}}$ is the volumetric rate of collapsed foam liquid flow; $Q_{\mathrm{e}}$ is the volumetric rate of the liquid contained in the collapsed foam liquid. Firstly a certain amount of the collapsed foam liquid was sampled carefully in a graduated cylinder at position A shown in Figure $1 . Q_{\mathrm{f}}$ was then determined by dividing the measured volume of the collapsed foam liquid with the sampled time. $Q_{\mathrm{e}}$ was determined by dividing the net liquid volume, measured by the spontaneous collapse of foam in the cylinder, with the sampled time.

\subsection{Power consumption for foam breaking, agita- tion, and aeration}

The shearing power $P_{\mathrm{s}}$, based on the shear force between the fixed orifice plate and the rotating disk, and the agitation power $P_{\mathrm{g}}$ in the gassed liquid, were determined with a spring-type torque meter. Aeration power $P_{\mathrm{a}}$ was calculated from the following equation (Satoh et al., 1989).

$$
P_{\mathrm{a}}=\rho_{\mathrm{L}} g U_{\mathrm{g}} V_{\mathrm{L}}
$$

\subsection{Gas holdup}

The mean gas holdup $\left(\varepsilon_{\mathrm{g}}\right)_{\mathrm{B}}$ in the bubble-dispersing section was determined by the manometric technique. The manometer reading was corrected for dynamic pressure changes (Sridhar and Potter, 1980). The mean gas holdup $\left(\varepsilon_{\mathrm{g}}\right)_{\mathrm{F}}$ in the foam-ascending section was estimated from Eq. (5) using the value of the liquid holdup in ascending foam, $\phi_{\mathrm{L}}$. No significant difference was observed in $\phi_{\mathrm{L}}$ values at different positions along the vessel height.

$$
\left(\varepsilon_{\mathrm{g}}\right)_{\mathrm{F}}=1-\phi_{\mathrm{L}}
$$

\subsection{Volumetric liquid-phase oxygen transfer coef- ficient}

Catalytic oxidation of a sodium sulfite solution with air was applied to measure the volumetric liquidphase oxygen transfer coefficient $k_{\mathrm{L}} a$. In this work, oxygen from air was absorbed into a $500 \mathrm{~mol} \cdot \mathrm{m}^{-3} \mathrm{so}-$ dium sulfite solution, $\mathrm{pH} 7.7$, and containing $1 \times 10^{-4}$ $\mathrm{mol} \cdot \mathrm{m}^{-3}$ cobalt sulfate. Two assumptions are made in deriving the absorption rate: 1) gas-side resistance to mass transfer is negligible; 2) Henry's law is applicable. In this catalytic oxidation of sodium sulfite solution, the oxygen absorption rate $N_{\mathrm{A}}$ is expressed as (Linek and Vacek, 1981)

$$
N_{\mathrm{A}}=k_{\mathrm{L}} a\left(\frac{P y}{H e}\right)
$$

where $P$ is the mean total pressure and $y$ is the oxygen mole fraction. The flow regime in the STR with the MFUS is divided into different two sections: the bubble-dispersing section, in which bubbles are dispersed uniformly in the bulk liquid; and the foam-ascending section, in which foams ascend continuously from the aerated liquid surface, as shown in Figure 3. Completely mixed flow and piston flow were assumed for the gas phase in the bubble-dispersing section and that in the foam-ascending section, respectively. The $k_{\mathrm{L}} a$ values were estimated from the oxygen mass balance in the vessel and Eq. (6).

The volumetric liquid-phase oxygen transfer coefficient $\left(k_{\mathrm{L}} a\right)_{\mathrm{B}}$ in the bubble-dispersing section was calculated as

$$
\left(k_{\mathrm{L}} a\right)_{\mathrm{B}}=\frac{G_{\mathrm{M}}^{+} \cdot H e \cdot S}{P \cdot V_{\mathrm{b}}} \cdot \frac{1}{y_{\mathrm{S}}} \cdot\left(\frac{y_{\mathrm{I}}}{1-y_{\mathrm{I}}}-\frac{y_{\mathrm{S}}}{1-y_{\mathrm{S}}}\right)
$$

where $G_{\mathrm{M}}{ }^{+}$and $V_{\mathrm{b}}$ are the molar flow rate of inert gas and the vessel volume in the bubble-dispersing section, respectively. The Henry's law constant $\mathrm{He}$ is based on the data of Rice and Benoit (1986).

The volumetric liquid-phase oxygen transfer coefficient $\left(k_{\mathrm{L}} a\right)_{\mathrm{F}}$ in the foam-ascending section was calculated as

$$
\left(k_{\mathrm{L}} a\right)_{\mathrm{F}}=\frac{G_{\mathrm{M}}^{+} \cdot H e}{P \cdot h_{\mathrm{f}}} \cdot\left[f\left(y_{\mathrm{S}}\right)-f\left(y_{\mathrm{O}}\right)\right]
$$




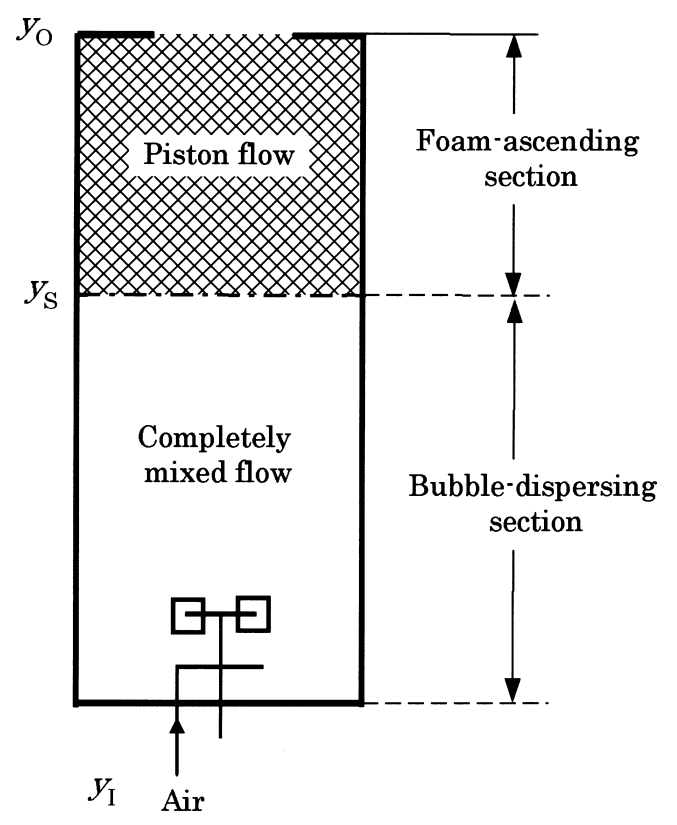

Fig. 3 A flow model of the gas phase

where

$$
f(y)=\ln \frac{y}{1-y}+\frac{1}{1-y}
$$

and $h_{\mathrm{f}}$ is the foam-ascending distance.

The oxygen mole fractions at the inlet of the vessel, the border of the two flow sections, and the outlet of the vessel, i.e., $y_{\mathrm{I}}, y_{\mathrm{S}}$, and $y_{\mathrm{O}}$, were measured with a magnetic oxygen analyzer (LF-700, Toray Engineering Co., Ltd.). In measurement of $y_{\mathrm{s}}$, the gas-liquid mixture was withdrawn through the glass tube packed with polyurethane foam from the sampling tap nearest the border of the two flow sections. It was separated completely into gas and liquid phases. The gas phase was only introduced into the oxygen analyzer and the liquid phase was returned to the vessel. The $\left(k_{\mathrm{L}} a\right)_{\mathrm{B}}$ values determined from the gas-phase balance equation, Eq. (7), concurred well with those measured according to the common sulfite oxidation method based on the concentration change of $\mathrm{Na}_{2} \mathrm{SO}_{3}$ in the liquid.

\section{Results and Discussion}

\subsection{Foam density before foam breaking}

Liquid holdup in foam, $\phi_{\mathrm{L}}$, which is necessary for the evaluation of foam density before foam breaking, $\rho_{a}$, was measured first. Figure 4 shows a typical relationship between $\phi_{\mathrm{L}}$ and the disk rotational speed $N$. $\phi_{\mathrm{L}}$ decreased with increasing $N$ and then became almost independent of $N$. Using the measured values of $\phi_{\mathrm{L}}, \rho_{\mathrm{a}}$ was calculated from Eq. (1). The relationship between

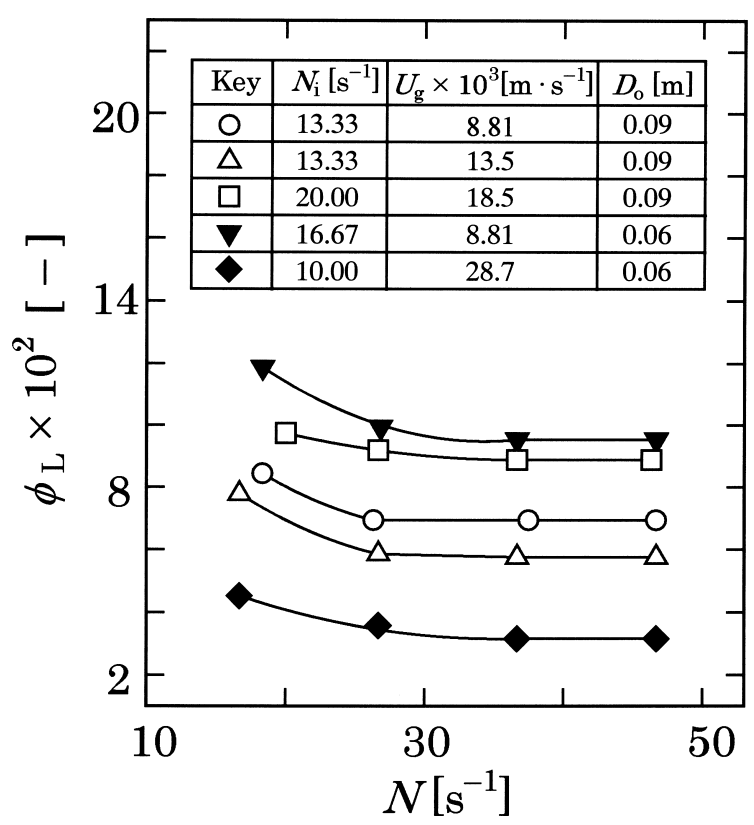

Fig. 4 The effect of disk rotation speed on liquid holdup in ascending foam

$\rho_{\mathrm{a}}$ and the gas superficial velocity $U_{\mathrm{g}}$ is shown in Figure 5, where $\rho_{\mathrm{a}}$ is based on the $\phi_{\mathrm{L}}$ value independent of $N . \rho_{\mathrm{a}}$ tended to decrease with increasing $U_{\mathrm{g}}$. Visual observation indicated that the size of foam in the ascending-foam section became larger as $U_{\mathrm{g}}$ increased in the same agitation rate condition. An increase in foam size decreases the liquid holdup (Hass and Johnson, 1965; Rubin et al., 1967). Therefore, smaller values of $\rho_{\mathrm{a}}$ at larger $U_{\mathrm{a}}$ are attributable to the decreased liquid holdup caused by an increase in the foam size. Regarding the effect of the impeller rotational speed $N_{\mathrm{i}}$ on $\rho_{\mathrm{a}}$, the value of $\rho_{\mathrm{a}}$ tended to increase with increasing $N_{\mathrm{i}}$. The increased foaming capacity with increasing $N_{\mathrm{i}}$ causes an increase of the ascending velocity of the foam. We can anticipate a larger liquid holdup because the downward liquid velocity with respect to the foam decreases as the ascending velocity of the foam increases, as a result the drainage rate of liquid from the foam decreases. Higher values of $\rho_{\mathrm{a}}$ at larger $N_{\mathrm{i}}$ may be attributable to the increased liquid holdup. $\rho_{\mathrm{a}}$ was also unaffected by orifice diameter, $D_{\mathrm{o}}$.

\subsection{Foam density after foam breaking}

Figure 6 shows a typical relationship between the ratio of the foam density (after foam breaking) to the liquid density $\rho_{\mathrm{f}} / \rho_{\mathrm{L}}$ and $N$. The value of $\rho_{\mathrm{f}} / \rho_{\mathrm{L}}$ tends to become higher as $U_{\mathrm{g}}$ increases and $N_{\mathrm{i}}$ decreases. In view of the change in $\rho_{\mathrm{a}}$ shown in Figure 5, the higher the $\rho_{\mathrm{a}}$, the smaller $\rho_{\mathrm{f}} / \rho_{\mathrm{L}}$ became. In addition, $\rho_{\mathrm{f}} / \rho_{\mathrm{L}}$ increased with the initial increase in $N$. Nevertheless, when $N$ became larger than a certain rotational speed, $\rho_{\mathrm{f}} / \rho_{\mathrm{L}}$ values were almost independent of $N$. This disk rotational speed at which $\rho_{\mathrm{f}} / \rho_{\mathrm{L}}$ began to level off was defined as the transitional disk rotational speed $N_{\mathrm{t}}$. To determine 


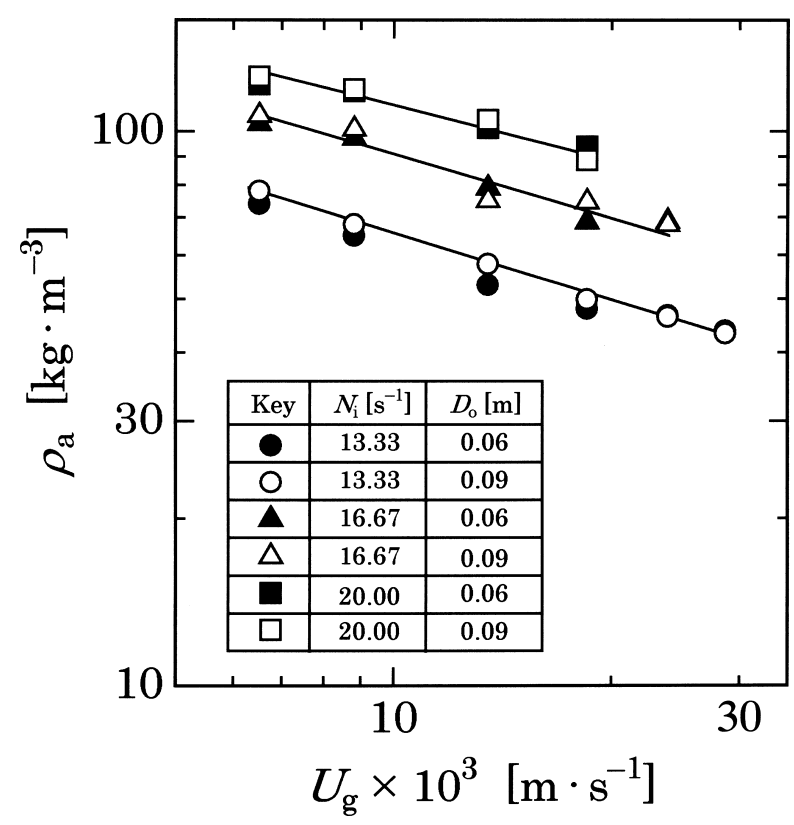

Fig. 5 Relationship between foam density before foambreaking and gas superficial velocity

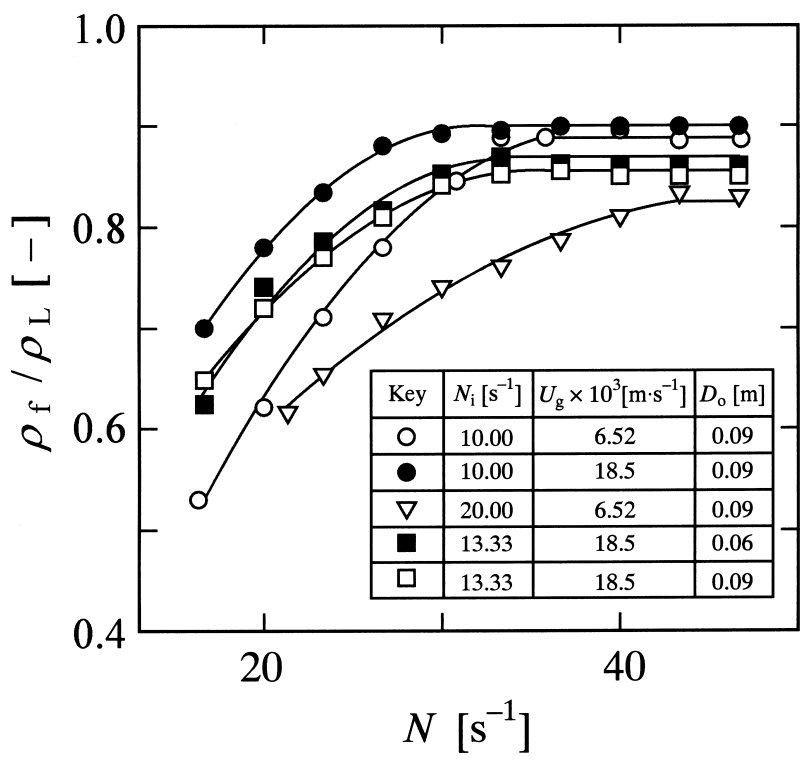

Fig. 6 Relationship between foam density after foam breaking and disk rotation speed

$N_{\mathrm{t}}, 1 /\left(\rho_{\mathrm{f}} / \rho_{\mathrm{L}}\right)$ replotted against $1 / N$ (Figure 7$) . N_{\mathrm{t}}$ values were obtained from intersections of the straight lines with different slopes. The maximum value of $\rho_{\mathrm{f}} / \rho_{\mathrm{L}}$ in the $N$ range above $N_{\mathrm{t}}$ at all operating conditions was 0.90 . This value may be dependent on the foam density before foam braking, $\rho$, and the velocity of the foam passing through the orifice. Figure 8 shows the typical relationship between $N_{\mathrm{t}}$ and $U_{\mathrm{g}} . N_{\mathrm{t}}$ decreases with increasing $U_{\mathrm{g}}$ and slightly increases as $N_{\mathrm{i}}$ increases. Regarding the effect of $D_{\mathrm{o}}$ on $N_{\mathrm{t}}$, a slight in-

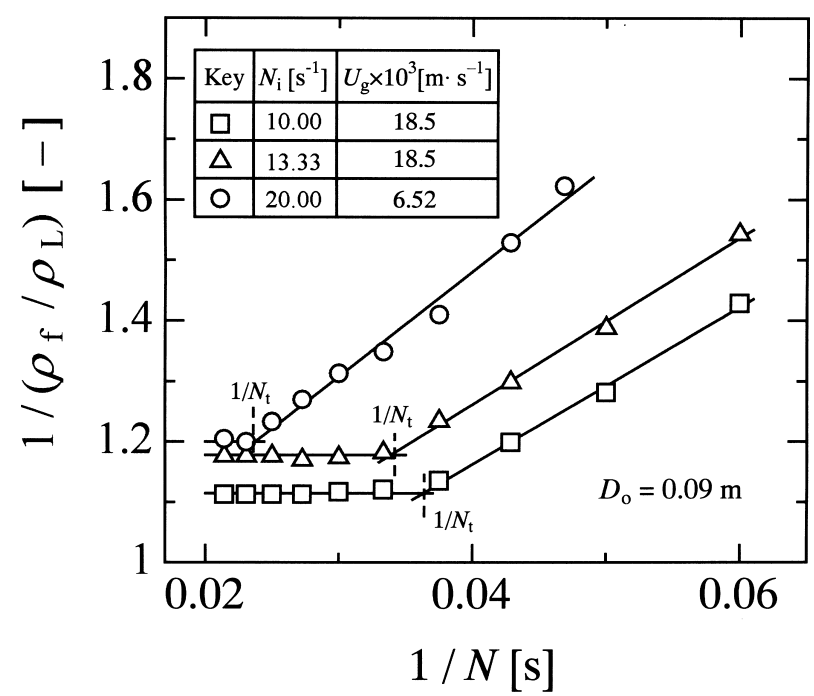

Fig. 7 Plot of $1 /\left(\rho_{\mathrm{f}} / \rho_{\mathrm{L}}\right)$ against $1 / N$

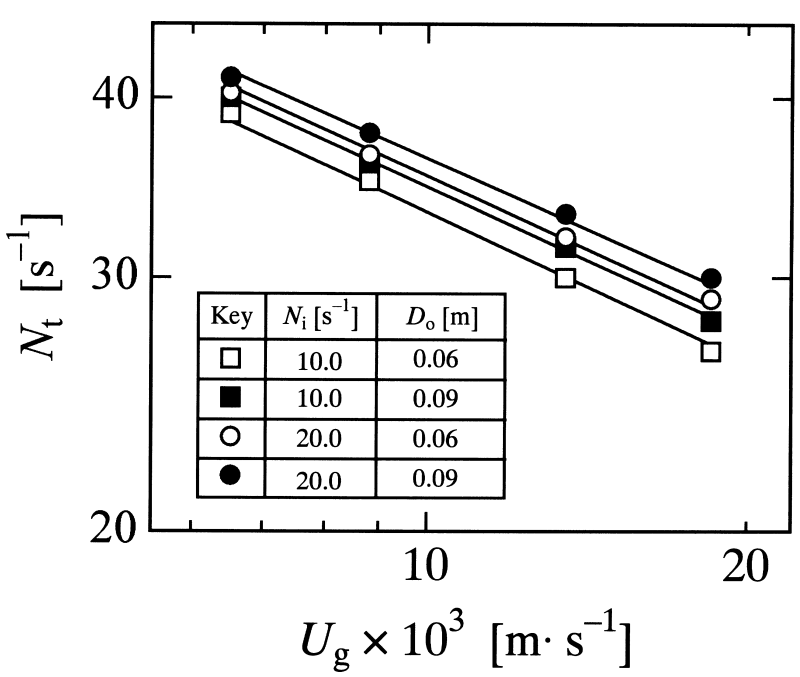

Fig.8 Relationship between transition disk rotational speed and gas superficial velocity

crease in $N_{\mathrm{t}}$ was observed as $D_{\mathrm{o}}$ increased. This increase may be attributable to a reduction of the area over which the shear force acts because of increased orifice diameter.

Within the range examined, correlation of $N_{t}$ was then carried out. By using operational parameters such as $U_{\mathrm{g}}, N_{\mathrm{i}}$ and $D_{\mathrm{o}} / D_{\mathrm{T}}$, the following equation was obtained within $\pm 10 \%$ error.

$$
N_{\mathrm{t}}=6.59 U_{\mathrm{g}}^{-0.33} N_{\mathrm{i}}^{0.08}\left(D_{\mathrm{o}} / D_{\mathrm{T}}\right)^{0.06}
$$

\subsection{Shearing power}

We investigated the change of the shearing power $P_{\mathrm{s}}$ required for the collapse of the foam flowing through the gap between the fixed orifice plate and the rotating 


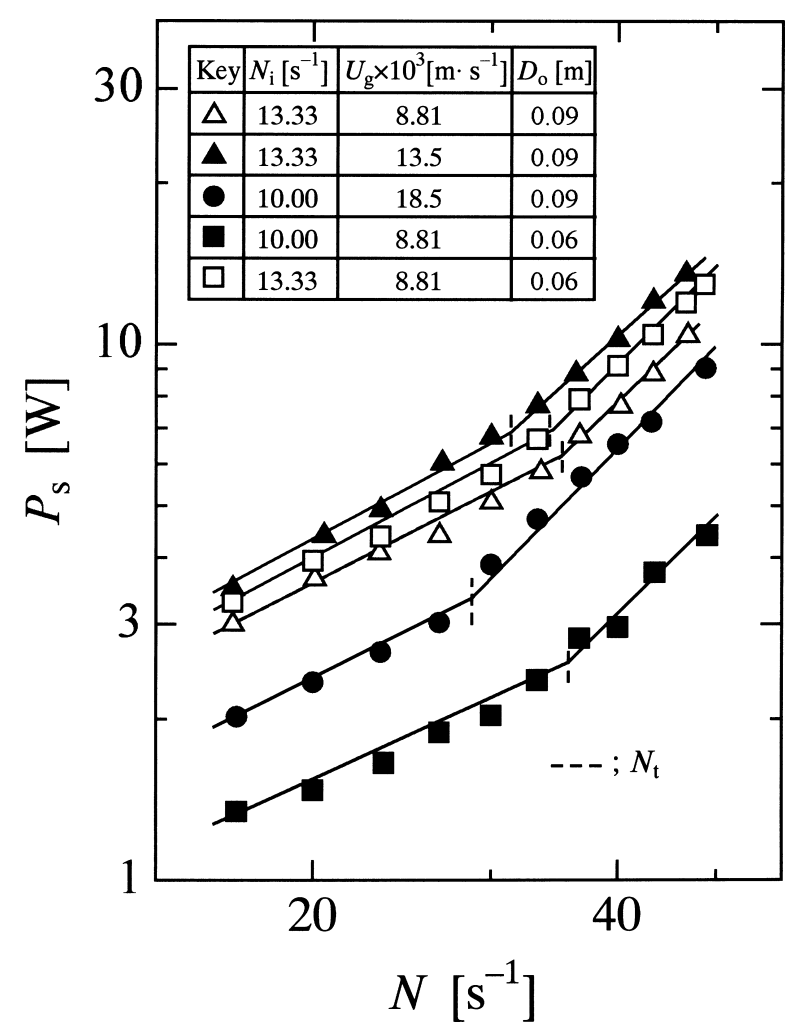

Fig. 9 Relationship between foam-breaking power and disk rotational speed

disk. Figure 9 shows the results of $P_{\mathrm{s}}$ plotted against $N$. $P_{\mathrm{s}}$ tended to be large with increasing $U_{\mathrm{g}}$ and $N_{\mathrm{i}}$. Because the volumetric rate of collapsed foam liquid flow $Q_{\mathrm{f}}$ after foam breaking increased with increasing $U_{\mathrm{g}}$ and $N_{\mathrm{i}}$, this tendency is inferred to result from the increased amount of foam liquid flow through the gap. Changing $P_{\mathrm{s}}$ also differed at $N$ below and above $N_{\mathrm{t}}$, as shown in the figure. When a disk made of transparent acrylic resin was used as a rotating disk, observations of the upper part of the rotating disk indicated the different behavior for the collapsing foam flow through the gap between the fixed orifice plate and the rotating disk at $N$ below and above $N_{\mathrm{t}}$. The collapsing foam path line at $N$ below $N_{\mathrm{t}}$ was curved gently toward the edge of the gap from the orifice, while at $N$ above $N_{\mathrm{t}}$ it was arched greatly. The difference of the change in $P_{\mathrm{s}}$ at $N$ below and above $N_{\text {t }}$ may be mainly attributed to the difference of the collapsing foam path line, i.e., the difference of the distance in which a shear force acts on the foam. Moreover, from both the results in this figure and those in Figure 6, it is clear that the disk most effectively operated at the transition disk rotational speed $N_{\mathrm{t}}$.

\subsection{Comparing foam-breaking performance of the} MFUS and existing mechanical foam-breakers: power for foam breaking

We compared the ratio of foam density after foam breaking to that before foam breaking, $\rho_{\mathrm{f}} / \rho_{\mathrm{a}}$, for the

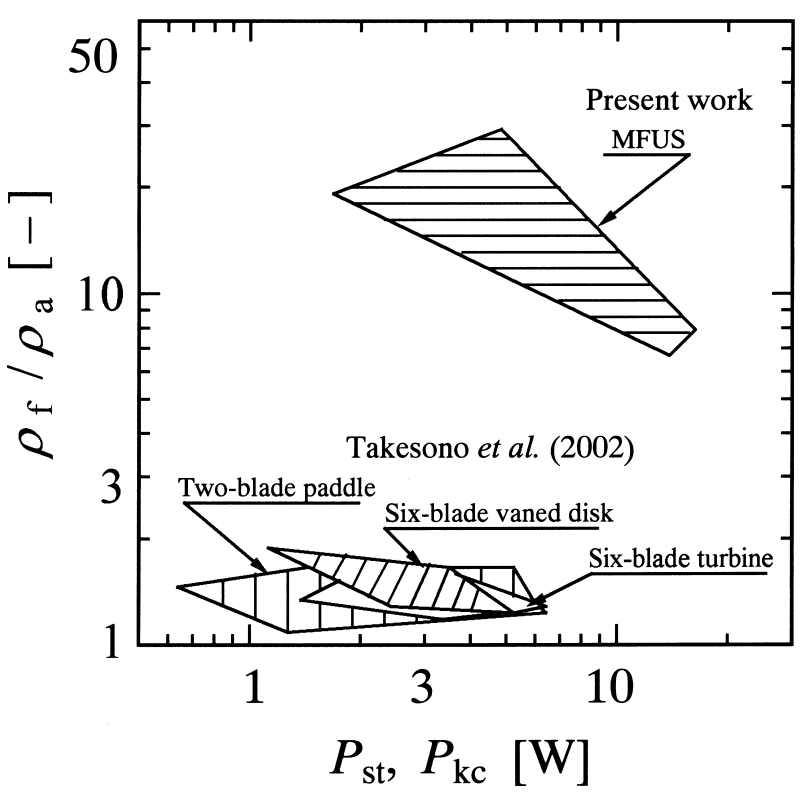

Fig. 10 Comparison of foam-breaking performance between MFUS and existing mechanical foam-breakers

MFUS and existing mechanical foam-breakers with rotating parts. Thereby, we determined their respective power for foam breaking. The shearing power $P_{\text {st }}$ at $N_{\mathrm{t}}$ in the MFUS and the foam-breaking power $P_{\mathrm{kc}}$ at the required critical rotational speed $N_{\mathrm{c}}$ (the minimum foam-breaking rotational speed sufficient to prevent the foam from rising above the foam-breaker level) in the existing mechanical foam-breakers were the criteria to measure foam-breaking power. Experimental conditions of the existing foam-breakers were $D_{\mathrm{T}}=$ $0.23 \mathrm{~m}, H_{\mathrm{L}}=D_{\mathrm{T}}, D_{\mathrm{FB}}=1 / 2 D_{\mathrm{T}}, U_{\mathrm{g}}=3.79 \times 10^{-3}-7.58 \times$ $10^{-3} \mathrm{~m} \cdot \mathrm{s}^{-1}, N_{\mathrm{i}}=6.67-30.0 \mathrm{~s}^{-1}$ and $0.01 \mathrm{vol} \%$ anionic soft detergent solution (Takesono et al., 2002). The foaming characteristic term of this detergent solution was almost identical to that of Triton X-100 solution used in the present work (Takesono et al., 1993a, 1993b). This similarity means that foaming characteristics of both solutions are very similar. Figure 10 shows the results of $\rho_{\mathrm{f}} / \rho_{\mathrm{a}}$ plotted against $P_{\mathrm{st}}$ or $P_{\mathrm{kc}}$. The $\rho_{\mathrm{f}} / \rho_{\mathrm{a}}$ values in the MFUS were considerably larger than those in the existing mechanical foam-breakers at the same level of power for foam breaking. This result suggests that the MFUS provides a higher level of foam-breaking performance while requiring less power.

\subsection{Gas holdup}

The gas holdup was examined in two sections: the bubble-dispersing and foam-ascending sections. Figure 11 shows typical results of the gas holdup, $\left(\varepsilon_{\mathrm{g}}\right)_{\mathrm{B}}$ and $\left(\varepsilon_{\mathrm{g}}\right)_{\mathrm{F}}$, in the bubble-dispersing and foam-ascending sections. In all the systems, $\left(\varepsilon_{\mathrm{g}}\right)_{\mathrm{B}}$ increased with increasing $N_{\mathrm{i}}$ and $U_{\mathrm{g}}$. In contrast, $\left(\varepsilon_{\mathrm{g}}\right)_{\mathrm{F}}$ in the foamascending section tended to become smaller as $N_{\mathrm{i}}$ increased and slightly larger as $U_{\mathrm{g}}$ increased. This 


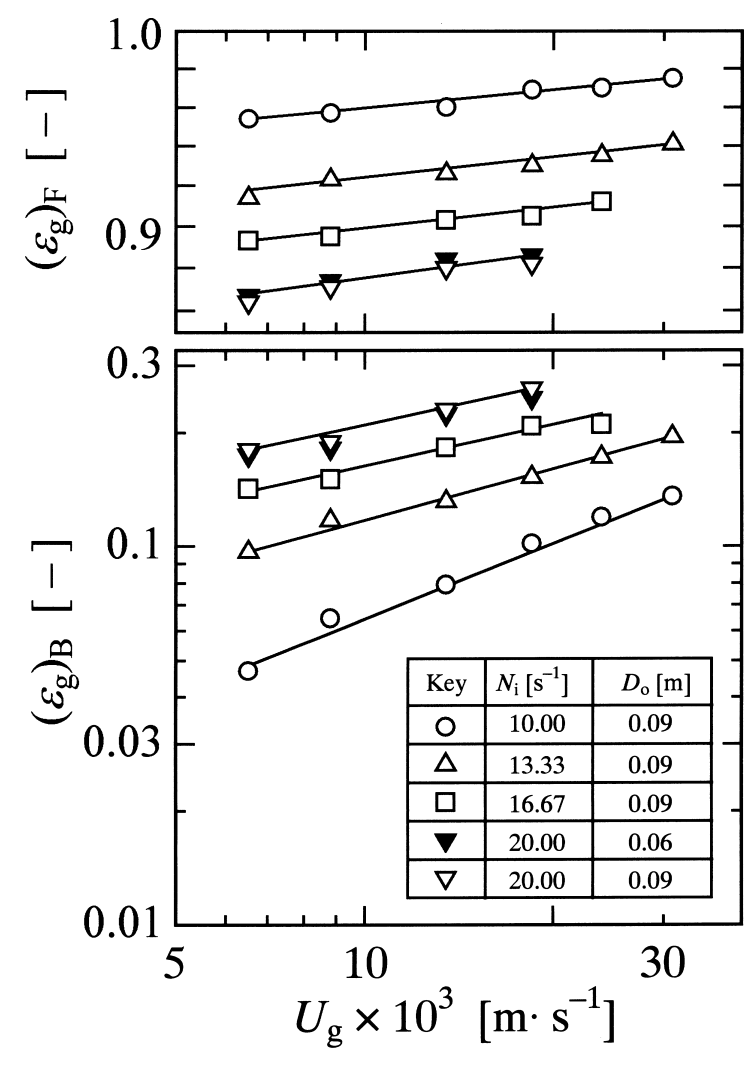

Fig. 11 Gas holdup in the bubble-dispersing and foamascending sections

tendency may result from the increase in $\phi_{\mathrm{L}}$ with increasing $N_{\mathrm{i}}$, which corresponds to the change of $\rho_{\mathrm{a}}$ shown in Figure 5. $\left(\varepsilon_{\mathrm{g}}\right)_{\mathrm{B}}$ and $\left(\varepsilon_{\mathrm{g}}\right)_{\mathrm{F}}$ were also independent of $D_{\text {. }}$.

\subsection{Volumetric liquid-phase oxygen transfer coef- \\ ficient}

Volumetric liquid-phase oxygen transfer coefficients $\left(k_{\mathrm{L}} a\right)_{\mathrm{B}}$ and $\left(k_{\mathrm{L}} a\right)_{\mathrm{F}}$ in the bubble-dispersing and foam-ascending sections were measured as $U_{\mathrm{g}}, N_{\mathrm{i}}$, and $D_{\mathrm{o}}$ were varied. Figure 12 shows the typical results of $\left(k_{\mathrm{L}} a\right)_{\mathrm{B}}$ and $\left(k_{\mathrm{L}} a\right)_{\mathrm{F}}$ plotted against $U_{\mathrm{g}}$. In both sections, the tendency of changing $k_{\mathrm{L}} a$ was found to correspond well to that of changing $\varepsilon_{\mathrm{g}}$ shown in Figure 11. The relationship between $k_{\mathrm{L}} a$ and the specific power input $P_{\mathrm{T}} / V_{\mathrm{L}}$ was then investigated. For comparison of $\left(k_{\mathrm{L}} a\right)_{\mathrm{B}}$, we referred to the results of Van't Riet (1979) for STR containing ionic solutions. Because $k_{\mathrm{L}} a$ data of the foam-ascending section in the STR have not been published, the result of $\left(k_{\mathrm{L}} a\right)_{\mathrm{F}}$ that Onda et al. (1969) measured in the foam column containing surfactant solutions was used for reference. Power input, $P_{\mathrm{T}}$, in the STR with the MFUS was evaluated as the sum of the power, $P_{\mathrm{st}}$, for foam breaking, the pneumatic power, $P_{\mathrm{a}}$, for gas input and the agitation power, $P_{\mathrm{g}} . P_{\mathrm{T}}$ values in the STR and the foam column were evaluated as the sum of $P_{\mathrm{a}}$ and $P_{\mathrm{g}}$, and only $P_{\mathrm{a}}$, respectively. Figure 13 shows the results of $\left(k_{\mathrm{L}} a\right)_{\mathrm{B}}$ and $\left(k_{\mathrm{L}} a\right)_{\mathrm{F}}$ plotted
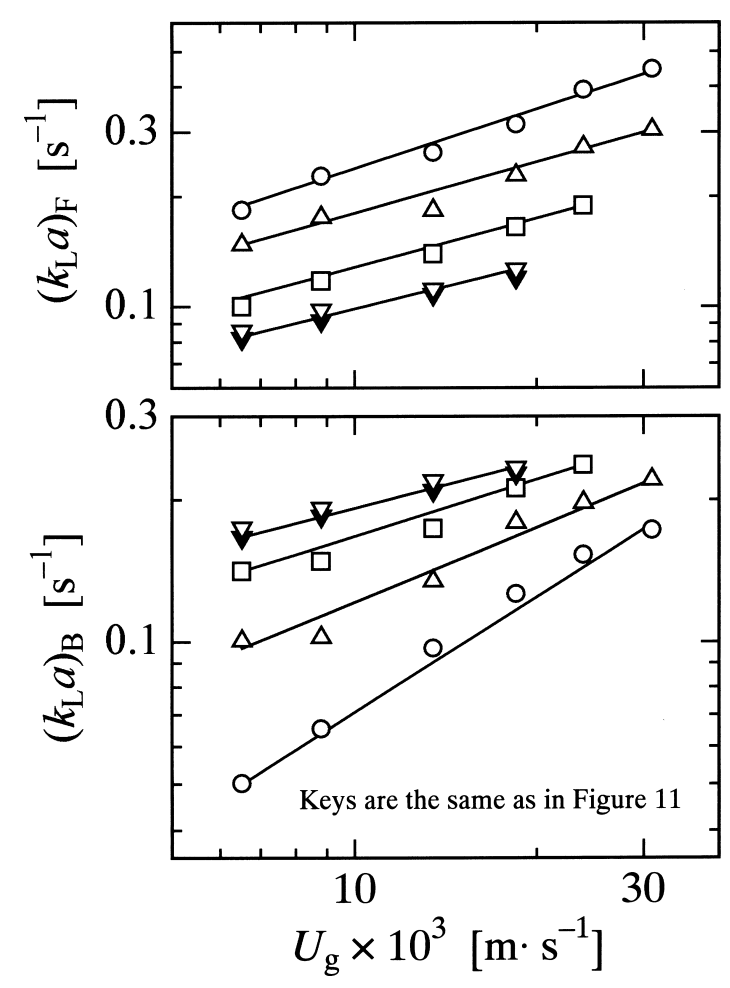

Fig. 12 Volumetric liquid-phase oxygen transfer coefficient in bubble-dispersing and foam-ascending section

against $P_{\mathrm{T}} / V_{\mathrm{L}}$, together with the results described above. That figure shows that $\left(k_{\mathrm{L}} a\right)_{\mathrm{B}}$ and $\left(k_{\mathrm{L}} a\right)_{\mathrm{F}}$ in the STR with the MFUS are large compared with those in other reactors at the same level of specific power input. That result supports the superiority of STR with the MFUS with respect to both mass transfer rate and power requirements. The STR with the MFUS demonstrated here, for which high oxygen transfer rate can be expected with reliable foam control, is considered to be useful as a reactor for those reactions with intense foaming.

\section{Conclusions}

We constructed a mechanical foam-breaker utilizing shear force (MFUS) between a fixed orifice plate and a rotating disk. It can prevent recirculation of persistent secondary foams. The foam-breaking performance of the MFUS was examined for a stirred-tank reactor (STR) containing a Triton X-100 solution. The ratio of the foam density after foam breaking to the liquid density $\rho_{\mathrm{f}} / \rho_{\mathrm{L}}$ increased as the disk rotation speed $N$ increased; however, when $N$ exceeded the transition disk rotational speed $N_{\mathrm{t}}, \rho_{\mathrm{f}} / \rho_{\mathrm{L}}$ was almost independent of $N$. The maximum value of $\rho_{\mathrm{f}} / \rho_{\mathrm{L}}$ was 0.90 within the present experimental condition. The ratio of foam density after foam breaking to that before foam breaking $\rho_{\mathrm{f}} / \rho_{\mathrm{a}}$ in the MFUS was considerably larger than that in the existing mechanical foam-breakers with rotating 


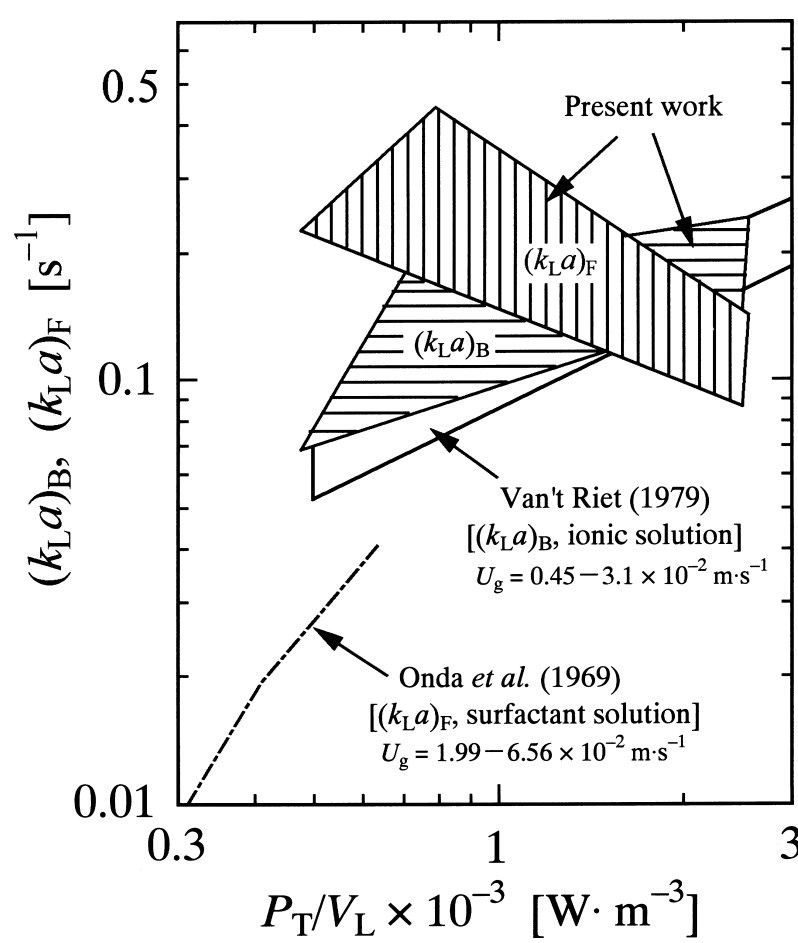

Fig. 13 Relationship between the volumetric liquid-phase oxygen transfer coefficient and a specific power input

parts at the same level of the power for foam breaking.

The gas holdup $\varepsilon_{\mathrm{g}}$ and volumetric liquid-phase oxygen transfer coefficient $k_{\mathrm{L}} a$ in the STR with the MFUS was evaluated separately in bubble-dispersing and foam-ascending sections. Comparison of $k_{\mathrm{L}} a$ for the STR with the MFUS and other reactors in terms of specific power input demonstrated higher oxygen transfer performance and lower power requirements for the STR with the MFUS.

\begin{tabular}{lllr}
\multicolumn{2}{l}{ Nomenclature } & \\
$D_{\mathrm{FB}}$ & $=$ & foam-breaker diameter & {$[\mathrm{m}]$} \\
$D_{\mathrm{o}}$ & $=$ & orifice diameter & {$[\mathrm{m}]$} \\
$D_{\mathrm{T}}$ & $=$ & column diameter & {$[\mathrm{m}]$} \\
$G_{\mathrm{M}}{ }^{+}$ & $=$ & superficial molar velocity of inert gas & \\
& & & {$\left[\mathrm{mol} \cdot \mathrm{m}^{-2} \cdot \mathrm{s}^{-1}\right]$} \\
$g$ & $=$ & gravitational acceleration & {$\left[\mathrm{m} \cdot \mathrm{s}^{-2}\right]$} \\
$H e$ & $=$ & Henry's law constant & {$\left[\mathrm{Pa} \cdot \mathrm{m}^{3} \cdot \mathrm{mol}^{-1}\right]$} \\
$H_{\mathrm{L}}$ & $=$ & static liquid height in a vessel & {$[\mathrm{m}]$} \\
$h_{\mathrm{f}}$ & $=$ & foam-ascending distance & {$[\mathrm{m}]$} \\
$k_{\mathrm{L}} a$ & $=$ & volumetric liquid-phase oxygen transfer coefficient \\
& & & {$\left[\mathrm{s}^{-1}\right]$} \\
$N$ & $=$ & disk rotational speed & {$\left[\mathrm{s}^{-1}\right]$} \\
$N_{\mathrm{A}}$ & $=$ & oxygen absorption rate per unit volume &
\end{tabular}

$N_{\mathrm{c}}=$ critical foam-breaker rotational speed required for foam breaking

$\left[\mathrm{s}^{-1}\right]$

$N_{\mathrm{i}} \quad=\quad$ impeller rotational speed

$N_{\mathrm{t}} \quad=$ transition disk rotational speed $\left[\mathrm{s}^{-1}\right]$

$\left[\mathrm{s}^{-1}\right]$

$=$ mean total pressure

$\begin{array}{ll}P_{\mathrm{a}} & =\text { pneumatic power of gas input } \\ P_{\mathrm{g}} & =\text { agitation power of gassed liquid }\end{array}$

$[\mathrm{Pa}]$

[W]

\begin{tabular}{|c|c|c|}
\hline$P_{\mathrm{kc}}$ & $=$ & $\begin{array}{l}\text { power consumed for foam breaking at a critical } \\
\text { state } \\
\text { [W] }\end{array}$ \\
\hline$P_{\mathrm{s}}$ & $=$ & power for foam breaking \\
\hline$P_{\text {st }}$ & $=$ & $\begin{array}{l}\text { power for foam breaking at a transition disk rota- } \\
\text { tional speed } \\
\text { [W] }\end{array}$ \\
\hline$P_{\mathrm{T}}$ & $=$ & power input \\
\hline$Q_{\mathrm{e}}$ & $=$ & $\begin{array}{l}\text { volumetric rate of the liquid contained in the col- } \\
\text { lapsed foam liquid }\end{array}$ \\
\hline$Q_{\mathrm{f}}$ & $=$ & $\begin{array}{l}\text { volumetric rate of the collapsed foam liquid flow } \\
\qquad\left[\mathrm{m}^{3} \cdot \mathrm{s}^{-1}\right]\end{array}$ \\
\hline$S$ & $=$ & cross-sectional area of a vessel \\
\hline$U_{\mathrm{g}}$ & $=$ & gas superficial velocity \\
\hline$V_{\mathrm{b}}^{\mathrm{g}}$ & $=$ & $\begin{array}{l}\text { vessel volume in the bubble-dispersing section } \\
{\left[\mathrm{m}^{3}\right]}\end{array}$ \\
\hline$V_{\mathrm{L}}$ & $=$ & working liquid volume \\
\hline$v_{\mathrm{f}}$ & $=$ & foam volume \\
\hline$v_{1}$ & $=$ & net liquid volume in $v_{\mathrm{f}}$ \\
\hline$y$ & $=$ & oxygen mole fraction \\
\hline$\varepsilon_{\mathrm{g}}$ & $=$ & gas holdup in the bubble-dispersing section $[-]$ \\
\hline$\rho_{\mathrm{a}}$ & $=$ & density of foam before foam breaking $\quad\left[\mathrm{kg} \cdot \mathrm{m}^{-3}\right]$ \\
\hline$\rho_{\mathrm{f}}$ & $=$ & $\begin{array}{l}\text { density of collapsed foam liquid after passing } \\
\text { through the orifice } \\
{\left[\mathrm{kg} \cdot \mathrm{m}^{-3}\right]}\end{array}$ \\
\hline$\rho_{\mathrm{g}}$ & $=$ & density of air \\
\hline$\rho_{\mathrm{L}}$ & $=$ & density of liquid \\
\hline$\phi_{\mathrm{L}}$ & $=$ & liquid holdup in ascending foam \\
\hline
\end{tabular}

$<$ Subscript $>$

$\begin{array}{ll}\mathrm{B} & =\text { bubble-dispersing section } \\ \mathrm{F} & =\text { foam-ascending section } \\ \mathrm{I} & =\text { inlet } \\ \mathrm{S} & =\text { surface } \\ \mathrm{O} & =\text { outlet }\end{array}$

\section{Literature Cited}

Andrew, S. P. S.; "Gas-Liquid Mass Transfer in Microbiological Reactors," Trans. Inst. Chem. Eng., 60, 3-13 (1982)

Boon, L. A., F. W. J. M. M. Hoeks, R. G. J. M. van der Lans, W. Bujalski, M. O. Wolff and A. W. Nienow; "Comparing a Range of Impellers for 'Stirring as Foam Disruption'," Biochem. Eng. J., 10, 183-195 (2002)

Deshpande, N. S. and M. Barigou; "Performance Characteristics of Novel Mechanical Foam Breakers in a Stirred Tank Reactor," J. Chem. Technol. Biotechnol., 74, 979-987 (1999)

Ghildyal, N. P., B. K. Lonsan and N. G. Karanth; "Foam Control in Submerged Fermentation," Adv. Microbiol., 33, 173-222 (1988)

Gutwald, S. and A. Mersmann; "Mechanical Foam Breaking-A Physical Model for Impact Effects with High Speed Rotors," Chem. Eng. Technol., 20, 76-84 (1997)

Hall, M. J., S. D. Dickinson, R. Pritchard and J. I. Evans; "Foams and Foam Control in Fermentation Processes," Prog. Ind. Microbiol., 12, 170-234 (1973)

Hass, P. A. and H. F. Johnson; "Foam Columns for Counter Current Surface-Liquid Extraction of Surface Active Solutes," AIChE J., 11, 319-324 (1965)

Hoeks, F. W. J. M. M., C. van Wees-Tangerman, K. Ch. A. M. Luyben, K. Gasser, S. Schmid and H. M. Mommers; "Stirring as Foam Disruption (SAFD) Technique in Fermentation Processes," Can. J. Chem. Eng., 75, 1018-1029 (1997)

Hoeks, F. W. J. M. M., L. A. Boon, F. Studer, M. O. Wolff, F. van der Schot, P. Vrabél, R. G. J. M. van der Lans, W. Bujalski, Å. Manelius, G. Blomsten, S. Hjorth, G. Prada, K. Ch. A. M. Luyben and A. W. Nienow; "Scale-up of Stirring as Foam Disruption (SAFD) to Industrial Scale," J. Ind. Microbiol. Biotechnol., 30, 118-128 (2003)

Koide, K., S. Yamazoe and S. Harada; "Effects of Surface-Active Substances on Gas Hold-Up and Gas-Liquid Mass Transfer in Bubble Column," J. Chem. Eng. Japan, 18, 287-292 (1985) 
Linek, V. and V. Vacek; "Chemical Engineering Use of Catalyzed Sulfite Oxidation Kinetics for the Determination of Mass Transfer Characteristics of Gas-Liquid Contactors," Chem. Eng. Sci., 36, 1747-1768 (1981)

Ng, K. S. and L. Gutierrez; "Mechanical Foam Breaker-Means for Foam Control in Wastewater Treatment," J. Water Pollut. Control Fed., 49, 2310-2317 (1977)

Onda, K., E. Sata and H. Takeuchi; "Specific Gas-Liquid Interfacial Area and Liquid-Phase Mass Transfer Coefficient in Foam Columns," Kagaku Kogaku, 33, 46-51 (1969)

Rice, R. G. and E. L. Benoit; “An Experimental Pressure-Response Method to Measure Gas-Liquid Kinetics," Chem. Eng. Sci., 41, 2629-2638 (1986)

Rubin, E., C. R. LaMantia and E. L. Gaden, Jr.; "Properties of Dynamic Foam Columns," Chem. Eng. Sci., 22, 1117-1125 (1967)

Satoh, K., Z. Yoshino and H. Shimada; "Gas Absorption Efficiency of Gas-Liquid Contactors with Mechanical Agitation," Kagaku Kogaku Ronbunshu, 15, 733-739 (1989)

Sridhar, T. and O. E. Potter; "Gas Holdup and Bubble Diameters in Pressurized Gas-Liquid Stirred Vessels," Ind. Eng. Chem. Fundam., 19, 21-26 (1980)

Takesono, S., M. Onodera, J. Nagai, K. Yamagiwa, A. Mori and A. Ohkawa; "Relation between Mechanical Foam-Breaking Dif- ficulty and the Foaming Characteristics of Solutions," J. Ferment. Bioeng., 75, 314-318 (1993a)

Takesono, S., M. Onodera, K. Yamagiwa and A. Ohkawa; "Design and Operation of Rotating-Disk Mechanical Foam-Breakers Fitted to Tower Fermenters," J. Chem. Technol. Biotechnol., 57, 237-246 (1993b)

Takesono, S., M. Onodera, A. Ito, M. Yoshida, K. Yamagiwa and A. Ohkawa; "Mechanical Control of Foaming in Stirred-Tank Reactors," J. Chem. Technol. Biotechnol., 76, 355-362 (2001)

Takesono, S., M. Onodera, M. Yoshida, K. Yamagiwa and A. Ohkawa; "Performance Characteristics of Mechanical FoamBreakers Fitted to a Stirred-Tank Reactor," J. Chem. Technol. Biotechnol., 78, 48-55 (2002)

Van't Riet, K.; "Review of Measuring Methods and Results in Nonviscous Gas-Liquid Mass Transfer in Stirred Vessels," Ind. Eng. Chem. Process Des. Dev., 18, 357-364 (1979)

Viesturs, U. E., M. Z. Kristason and E. S. Levitans; "Foams in Microbiological Processes," Adv. Biochem. Eng., 21, 169-224 (1982)

Yagi, H. and F. Yoshida; "Oxygen Absorption in FermentorsEffects of Surfactants, Antifoaming Agents and Sterilized Cells," J. Ferment. Technol., 52, 905-916 (1974) 